Editorial

\title{
Luca Cavalli-Sforza, 100 years after his birth
}

\author{
Lounès Chikhi 1,2 and Guido Barbujani 3,*
}

1. Laboratoire Évolution \& Diversité Biologique (EDB UMR 5174), CNRS, IRD, UPS, Université de Toulouse Midi-Pyrénées, Toulouse, France;

E-Mail: lounes.chikhi@univ-tlse3.fr

2. Instituto Gulbenkian de Ciência, Oeiras, Portugal;

E-Mail: chikhi@igc.gulbenkian.pt

3. Department of Life Sciences and Biotechnology, University of Ferrara, Via L. Borsari 46, 44121, Ferrara, Italy

* Correspondence: Guido Barbujani; E-Mail: g.barbujani@unife.it

Received: 23 Sep 2021

Accepted: 27 Sep 2021

Published: 16 Oct 2021

Copyright: (c) 2021 by the author(s). This is an Open Access article distributed under the terms of the Creative Commons License Attribution 4.0 International (CC BY 4.0), which permits unrestricted use, distribution, and reproduction in any medium or format, provided the original work is correctly credited.

Publisher's Note: Pivot Science Publication Corp. remains neutral with regard to jurisdictional claims in published maps and institutional affiliations.
It is a beautiful, sunny afternoon in June 2004, and we are sitting in a conference room of the Maison du Haut Salat, in the Pyrenees, south of France in the small village of Seix, $100 \mathrm{~km}$ from Toulouse. Next to us in the room is the little crowd of geneticists and archaeologists concentrating on a talk. Mark Thomas, Rosalind Harding, Laurent Excoffier, Stephen Shennan, Francesco d'Errico, João Zilhão, Martha Lahr, the late Henry Harpending, and Alex Bentley are all watching silently. In that late afternoon, despite a long day of discussions and presentations, we are all captivated by a youthful eighty-two-year-old population geneticist who is sharing with us the results of a study he just published in the prestigious Proceedings of the National Academy of Sciences of the USA. He is explaining to this fascinated audience some of his results on the genetics of populations located at the edge of the geographical range of a demographic expansion. He does not use very sophisticated visual tools. It's all simple. He draws a wave, a dot, and explains how mutations may be surfing on the expanding wave. He shows how genetic drift taking place in these edge populations as they colonize new lands can generate major changes in allele frequency. By bringing mutations that were rare in the expanding source population to a high frequency, he shows how spatial expansions may leave a very specific signature that geneticists can then use to infer aspects of population history or, as Edmonds et al. wrote [1], to "reconstruct migratory trajectories"-a life-long search of Cavalli-Sforza's. Edmonds' work also showed how such a signature could be mistaken for the result of an adaptation process: the rapid increase of a mutation that was rare in other regions could easily and wrongly be interpreted as the effect of positive selection. 
Henry Harpending would comment later that day on the fact that it was simply amazing that such a simple and beautiful idea had escaped so many researchers. You could feel the respect he had for the eighty-twoyear-young man. Years later we still experience that awe for Luca Cavalli-Sforza, who had studied with R.A. Fisher, one of the most important theoretical population geneticists of the 20th century. Cavalli had also worked on recombination in bacteria with Nobel Prize winner, Joshua Lederberg [2], and applied the theoretical work of Fisher to study the Neolithic transition with Albert J. Ammerman [3]. He, together with Paolo Menozzi and Alberto Piazza, brought together all the genetic data available on human populations in one of the most impressive encyclopedic works done in the 1990s [4]. Starting with that study, Cavalli revolutionized the field of human population genetics, bringing together linguistics, genetics and archaeology, among many other contributions. It is a common thing in the field of human population genetics to discover that articles published today are based on ideas that Luca Cavalli-Sforza had 30 or even 60 years ago. On that warm afternoon of 2004, he had once again made one important step before all of us, recognizing in the interaction of genetic drift and spatial processes, something that we all had missed.

It is a pleasure and an honour to present this Special Issue in memory of the most influential human population geneticist ever. To assemble this Special Issue, we asked colleagues, renowned and promising researchers in the field, to start from a classical article or book of Cavalli-Sforza, and then provide either a review, opinion or historical perspective on it. We shall not go through all the contributions here, but we are lucky to have had positive responses of such quality. Marcus Feldman wrote about a study he co-authored with Cavalli-Sforza, providing both the historical perspective and a new analysis. Gwenna Breton, Cesar Fortes-Lima and Carina Schlebusch wrote a review based on the original work of CavalliSforza on Central African hunter-gatherer populations. Not only did the authors review the current literature, but they utilized genomic data to revisit the very questions asked by Cavalli-Sforza more than 50 years ago. While confirming the general results, they also showed how far we have come since then. Melinda Yang accepted the challenge to start from one of the few studies addressing the human demographic history of Asia. Her article not only reminds us of how little was known when CavalliSforza published his study in 1999, but also provides a timely review of the current state of the art. Joaquim Fort, a physicist working on spatial processes in archeology, took on the hard task of giving a thorough account of the work that resulted in Ammerman and Cavalli Sforza's seminal book on the Neolithic transition. Joe Felsenstein was kind enough to share a previous paper he wrote in honour of Edwards and Cavalli-Sforza on the article in which they basically started what would become modern molecular statistical phylogenetics. Felsenstein not only 
provides a unique analysis, but also generously shared a little known story on the origins of that paper.

We also asked Jonathan Marks, an anthropologist, and Giuseppe Longobardi, a linguist, to write review papers on Cavalli-Sforza's impact on their fields. Hoping that they will not hide areas of disagreement, as is justly fair, we are excited to see their contributions.

Luca Cavalli-Sforza, was not just the most important human population geneticist of the 20th century; he has been paving the ground for research that has influenced the field for decades, well into the new millennium. Cavalli-Sforza was often to be found in the most interesting place before everybody else. He was among the first to think in genomic terms, and to recognize the importance of both spatial and temporal factors in the evolution of genetic diversity. He thought originally, sharply, and with an incredible ability to foresee and shape future developments. It would not be far off to say that his intuition was probably the most impressive of his talents, but it was an intuition guided by a profound biological culture and a very deep understanding of quantitative processes. He thought both quantitatively and qualitatively-something that very few can do (Richard Lewontin, who left us this year and may not have always agreed with Cavalli-Sforza, comes to mind). Luca knew the difference between what could make sense, and what could be demonstrated. He also knew sometimes how to convince, even when he did not really have the data to do it. He often showed the way. He was there before all of us. And we are all indebted to him for that.

Finally, we are happy to announce that Luca and Alba Cavalli-Sforza's children have created a website to further their father's work and honor his memory. They are proud to make it public at the same time as the first issue of this journal appears. The website displays:

- almost 500 scientific papers written by their father, made accessible through a simple filtering system by general subjects and subcategories; - a complete list of his books, as originally published;

- biographies of their father;

- and the complete set of the talks given in his memory by dozens of colleagues, friends and relatives on March 30, 2019. The celebration took place at Collegio Ghislieri, in Pavia, where Luca studied when at university. The website is open to anyone and requires no registration: https://lucacavallisforza.com.

With this Special Issue we would like to provide an introduction to Luca Cavalli-Sforza's groundbreaking work. It also seems the best way for this new, forward-looking journal of human population genetics and genomics to get started. 


\section{References}

1. Edmonds CA, Lillie AS, Cavalli-Sforza LL. Mutations arising in the wave front of an expanding population. Proc Natl Acad Sci USA 2004;101:975-979. DOI

2. Cavalli-Sforza LL, Lederberg J. Isolation of pre-adaptive mutants in bacteria by sib selection. Genetics 1956;41:367-381. DOI

3. Ammerman AJ, Cavalli-Sforza LL. The Neolithic Transition and the Genetics of Populations in Europe. Princeton, NJ, USA: Princeton University Press. 1984. DOI

4. Cavalli-Sforza LL, Piazza A, Menozzi P. The History and Geography of Human Genes. Princeton, NJ, USA: Princeton University Press. 1995. DOI

Cite this article: Chikhi L, Barbujani G. Luca Cavalli-Sforza, 100 years after his birth. Hum Popul Genet Genom. 2021;1(1): 0001. https://doi.org/10.47248/hpgg2101010001 